\title{
influencia de la cocción y enfriamiento del clínker de cemento portland sobre su estructura
}

(Einfluss der Brennweise und der Kühlung auf die Struktur des Portlandzementklinkers)

O. M. ASTREEWA

De: «Tsement», vol. 22, núm. 4, 1956, pág: 21*

El autor ha estudiado la influencia de la forma en que se lieva a cabo la cocción sobre la formación de los minerales del clinker. Las conclusiones a que llega son las stgulentes: Cuanto más tiempo permanece el clinker en la zona de sinterización, tanto mayor es el contenido de $\mathrm{Al}_{z} \mathrm{O}$. en el C.AF, y tanto más disminuye la proporción de $\mathrm{C}_{\mathrm{S}} \mathrm{A}$ y crece la de $\mathrm{C}_{\mathrm{a}} \mathrm{S}$. Por lo tanto, el $\mathrm{C}_{4} \mathrm{AF}$ tiene en el clínker una composición intermedia entre $2 \mathrm{CaO}, \mathrm{Fe}_{2} \mathrm{O}_{4}$ y $8 \mathrm{CaO}, 3 \mathrm{Al}_{2} \mathrm{O}_{3}$. $\mathrm{El} \mathrm{C}_{2} \mathrm{~A}$, que se forma en primer lugar, deja $\mathrm{CaO}$, que forma $\mathrm{C}_{7} \mathrm{~S}$ a partir del $\mathrm{C}$ s; en el ferrito aluminato se disuelve, principalmente, el $5 \mathrm{CaO} .3 \mathrm{Al}_{2} \mathrm{O}_{3}$.

Incluso la estructura de los minerales del clínker puede ser diferente. Si el contenido en álcalis es elevado, los cristales hexagonales de $\mathrm{C}_{n} \mathrm{~S}$ adquieren una forma redonda. Si el tiempo de permanencta del clinker en la zona de sinterización es pequeño, el $C_{2}$ s se enriquece en $C_{8} S$ : el $C_{2} S$ no se satura con CaO. Las muestras tomadas simultáneamente del enfriador contienen menos $\mathrm{C} . \mathrm{S}$. Si el enfriamiento se ha llevado a cabo rápidamente, los granos de belita se han redondeado, mientras que si ha transcurrido lentamente, presentan bordes desgarrados, habiéndose partido los granos en otros más pequeños. Los bordes de los cristales de alita presentan belita, de procedencia secundaria, que se ha formado con separactón de $\mathrm{CaO}$.

A lo largo del recorrido por el horno, los granos de belita, formados a partir de finas esferolitas, van creciendo; después, por enfriamiento lento, vuelven a fraccionarse.

Cuando el enfriamiento tiene lugar lentamente, aparece periclasa en forma de granos grandes; mientras que si el enfriamiento es rápido, los granos son pequeños y se encuentran aglomerados.

Se comprende, por tanto, que si se desean determinar las propiedades de un clínker, es necesario examinar su estructura.

S. F. S.

\footnotetext{
* Fn wSilikattechnik», vol, 8, núm. 1, enero 1957, pag. 36.
} 